\title{
Ultratrace-level determination of glyphosate, aminomethylphosphonic acid and glufosinate in natural waters by solid-phase extraction followed by liquid chromatography-tandem mass spectrometry: performance tuning of derivatization, enrichment and detection
}

\author{
Irene Hanke • Heinz Singer • Juliane Hollender
}

Received: 1 February 2008 /Revised: 7 April 2008 /Accepted: 11 April 2008 / Published online: 16 May 2008

(C) Springer Verlag 2008

\begin{abstract}
A sensitive and robust analytical method for the quantification of glyphosate, aminomethylphosphonic acid (AMPA) and glufosinate in natural water has been developed on the basis of a derivatization with 9fluorenylmethylchloroformate (FMOC-Cl), solid-phase extraction (SPE) and liquid chromatography followed by electrospray tandem mass spectrometry (LC-ESI-MS/MS). In order to maximize sensitivity, the derivatization was optimized regarding organic solvent content, amount of FMOC-Cl and reaction time. At an acetonitrile content of $10 \%$ a derivatization yield of $100 \%$ was reached within two hours in groundwater and surface water samples. After a twofold dilution the low acetonitrile content allowed solidphase extraction of a sample of originally $80 \mathrm{~mL}$ over $200 \mathrm{mg}$ Strata-X cartridges. In order to decrease the load of the LC column and mass spectrometer with derivatization by-products (e.g., 9-fluorenylmethanol FMOC-OH), a rinsing step was performed for the SPE cartridge with dichloromethane. Acidification of the sample and addition of EDTA was used to minimize complexation of the target compounds with metal ions in environmental samples. Due to the large sample volume and the complete FMOC-OH removal, limits of quantification of $0.7 \mathrm{ng} / \mathrm{L}, 0.8 \mathrm{ng} / \mathrm{L}$ and $2.3 \mathrm{ng} / \mathrm{L}$ were achieved in surface water for glyphosate, AMPA and glufosinate, respectively. The limits of detection were as low as $0.2 \mathrm{ng} / \mathrm{L}, 0.2 \mathrm{ng} / \mathrm{L}$ and $0.6 \mathrm{ng} / \mathrm{L}$ for
\end{abstract}

I. Hanke $\cdot$ H. Singer $(\bowtie) \cdot J$. Hollender

Eawag, Environmental Chemistry,

Ueberlandstrasse 133,

8600 Duebendorf, Switzerland

e mail: heinz.singer@eawag.ch glyphosate, AMPA and glufosinate, respectively. Surface water and ground water samples spiked at $2 \mathrm{ng} / \mathrm{L}$ showed recoveries of $91-107 \%$.

Keywords Glyphosate ·AMPA W Water · Solid-phase extraction - Liquid chromatography - Tandem mass spectrometry

\section{Introduction}

Glyphosate [N-(phosphonomethyl)glycine] was introduced more than 30 years ago and has become one of the most important pesticides in the world. It is a broad-spectrum, nonselective, post-emergence herbicide. Glyphosate reaching the soil sorbs strongly to soil components such as clay minerals, iron oxides or humic acids [1-4] and degrades rapidly to aminomethylphosphonic acid (AMPA) [5]. Although glyphosate and AMPA are thus not expected to be exported to groundwater and surface water, both were detected at levels of up to several $\mu \mathrm{g} / \mathrm{L}$ in surface water [6]. Despite the fact that glyphosate has a lower ecotoxicological potential than many other herbicides, a thorough assessment of its environmental occurrence is necessary given its increased application. The less frequently used herbicide glufosinate [2-amino-4-(hydroxymethylphosphinyl)butyric acid] was studied as well, since its chemical structure is similar to that of glyphosate.

Detection of glyphosate at trace levels in environmental samples is difficult due to its zwitterionic structure and its complexation with metal ions. Analytical methods based on gas chromatography coupled to mass spectrometry are sensitive, but the sample preparation is tedious, as all ionic 
groups must be derivatized [7-9]. Liquid chromatography coupled to tandem mass spectrometry (LC-MS/MS) is currently the method of choice for polar analytes due to its high selectivity and sensitivity. However, when using LC-MS/MS, derivatization of glyphosate and AMPA is still required to enable analysis and enrichment by reversedphase (RP) sorbent phases. Fluorenylmethylchloroformate (FMOC-Cl) is the most common pre-column derivatization reagent used in combination with LC-MS/MS [10-13]. Enrichment of glyphosate by solid-phase extraction on an RP cartridge is carried out to obtain an adequate sensitivity for the analysis of natural water samples. Typically, sample volumes of between $4 \mathrm{~mL}$ and $50 \mathrm{~mL}$ are solid-phase-extracted on $\mathrm{C} 18$ modified silica gel or polymeric cartridges and the FMOC derivates are detected in positive or negative ion mode $[10,11$, 14]. The most sensitive methods reach a limit of quantification (LOQ) of $50 \mathrm{ng} / \mathrm{L}$ for glyphosate in natural waters $[10,11]$. In order to assess its fate and behavior in groundwater and surface water, a method is needed that is able to reliably quantify below the current limits of quantification of $50 \mathrm{ng} / \mathrm{L}$. Performance tuning of the FMOC-Cl-based method is clearly necessary to achieve this.

The reported reaction times of glyphosate with FMOC-Cl range from $30 \mathrm{~min}$ [15] to several hours [10, 11]. Other parameters affecting reaction yield and kinetics, i.e., temperature, concentration of derivatization reagent and proportion of organic solvent to water, also vary considerably throughout the literature. Nedelkoska and Low [16] evaluated in detail the appropriate content of organic modifier needed to achieve complete derivatization. A low content of the organic solvent is necessary for the enrichment of higher sample volumes on a reversed-phase SPE cartridge in order to reach higher sensitivity. However, under the condition that the lowest possible organic solvent content is used, no detailed studies of the kinetics and yield of the reaction of glyphosate with FMOC-Cl have been published so far.

A further challenge of the derivatization reaction with FMOC-Cl is the formation of derivatization by-products like FMOC-OH, which is formed by hydrolysis and decarboxylation of the FMOC-Cl. These by-products might hamper further sample preparation as they are less water soluble than the derivatized analytes and potentially impair the chromatographic column due to precipitation. Furthermore, they lower the ionization efficiency and thus affect the robustness and sensitivity of the overall method. Prevention strategies that involve choosing appropriate conditions during the derivatization or removal strategies that entail using an FMOC-OH selective extraction procedure are urgently needed for a reliable method. Short reaction times and lower temperatures seem to minimize FMOC-OH formation [16, 17]. Some studies have used a time- and solvent-consuming liquid-liquid extraction step for the removal of FMOC-OH after derivatization [18, 19], while others removed FMOC-OH during the elution from the SPE cartridge using online coupling of the SPE cartridge to the LC column [14, 20]. A fast and effective removal step for the by-products in classical offline SPE is still missing.

In order to enhance the sensitivity and to simplify and shorten the derivatization as well as the clean-up procedure for an FMOC-based offline SPE-LC-MS/MS method, the following aspects were studied. The derivatization step with FMOC-Cl was optimized to determine the shortest derivatization time with the most suitable SPE enrichment efficiency to achieve the best sensitivity. Furthermore, the FMOC-OH separation on the SPE column was elaborated to obtain a short and robust LC-MS/MS method. Multivalent cations present in environmental matrices, especially in groundwater, may also decrease the method performance by forming complexes with the analytes which elude derivatization with $\mathrm{FMOC}-\mathrm{Cl}$, enrichment or detection. In addition to the acidification proposed in [21], a few experiments that involved the addition of EDTA to minimize the reformation of complexes based on the results of Freuze et al. [22] were carried out.

\section{Materials and methods}

\section{Chemicals}

Glyphosate (98\%), AMPA (98\%), glufosinate ammonium (97\%), glyphosate-FMOC (98.5\%), AMPA-FMOC (97\%), glufosinate-FMOC $(98.5 \%)$ and the isotope labeled standards (ILS) $1,2-{ }^{13} \mathrm{C}_{2}{ }^{15} \mathrm{~N}$ glyphosate $(98 \%)$ and ${ }^{13} \mathrm{C}{ }^{15} \mathrm{~N}$ AMPA (99\%) were obtained from Dr. Ehrenstorfer (Augsburg, Germany). Individual stock solutions for all compounds with concentrations of $1 \mu \mathrm{g} / \mu \mathrm{L}$ were prepared in water, except for the FMOC-derivate standards, which were prepared in $\mathrm{MeOH}$. The stock solutions and the dilutions were stored at $4{ }^{\circ} \mathrm{C}$. Mixture solutions with concentrations of $0.1,1$ and $10 \mathrm{ng} / \mu \mathrm{l}$ of the analytes ("Mix-STD") and of the FMOC-derivates ("Mix-FMOC") were prepared in water and $\mathrm{MeOH}$, respectively. These were used as spike solutions for sample fortification and for the calibration standards. The internal standard mixture solution was prepared in water with a concentration of $0.05 \mathrm{ng} / \mu \mathrm{l}$.

HPLC-grade methanol, acetonitrile and water were used (Scharlau, Barcelona, Spain). Formic acid (FA, 98-100\%), dichloromethane p.a., ammonia p.a. $\left(\mathrm{NH}_{3}, 25 \%\right)$, sodium tetraborate p.a., potassium hydroxide p.a. $(\mathrm{KOH})$ and hydrochloric acid p.a. $(\mathrm{HCl}, 32 \%)$ were purchased from Merck (Darmstadt, Germany). Fluorenylmethylchloroformate puriss. p.a. (FMOC-Cl) and tetrasodium ethylenediaminetetraacetic acid (EDTA, purity $>99 \%$ ) were obtained from Sigma-Aldrich (Buchs, Switzerland). 
For derivatization, a $6.5 \mathrm{mM}$ FMOC-Cl stock solution and a $40 \mathrm{mM}$ borate buffer were used. The FMOC-Cl solution was prepared daily by dissolving $168 \mathrm{mg}$ of FMOC-Cl in $100 \mathrm{~mL}$ of acetonitrile. To obtain the $40 \mathrm{mM}$ borate buffer, $4 \mathrm{~g}$ of sodium tetraborate were dissolved in $500 \mathrm{~mL}$ of water at $50{ }^{\circ} \mathrm{C}$ in an ultrasonic bath. The buffer was kept at $4{ }^{\circ} \mathrm{C}$. A $1.0 \mathrm{M}$ stock solution of EDTA was obtained by dissolving $41.6 \mathrm{~g}$ of EDTA in $100 \mathrm{~mL}$ water. A $0.5 \mathrm{M}$ stock solution of ammonium acetate for the mobile phase for liquid chromatography was prepared in water. To obtain the aqueous mobile phase, the stock solution was diluted with water to $5 \mathrm{mM}$ and adjusted with $\mathrm{NH}_{3}$ to $\mathrm{pH} 9$.

\section{Environmental samples}

For method validation at low concentrations, environmental water samples with very low levels of glyphosate and AMPA were required. As glyphosate is intensively used in most parts of the Swiss plateau, the majority of surface waters were expected to contain a significant level of glyphosate and its main metabolite. Thus, surface water samples were taken from a small brook with minimal anthropogenic impact in a remote alpine region ("Val Roseg") on August 23, 2006. Additionally, water from the epilimnion of Lake Zurich was sampled on December 20, 2007. This lake is only marginally influenced by agriculture and is thus expected to show lower levels of glyphosate.

To investigate the occurrence of glyphosate and AMPA in agricultural and urban areas, different samples were collected from river, lake and ground waters.

On July 13 and August 10, 2006, water samples were collected above the deepest point of Lake Greifensee and Lake Murtensee at different depths. Additionally, five grab samples from the tributaries of both lakes were taken between July and August 2006. Both lakes are located in the Swiss plateau. The catchment of Lake Greifensee has a size of $160 \mathrm{~km}^{2}$, of which $54 \%$ is used for agriculture. Approximately 100,000 habitants live in this area. The catchment of Lake Murtensee with 76,000 inhabitants and an area of $693 \mathrm{~km}^{2}$ is less densely populated, but is also dominated by agriculture ( $69 \%$ of the area). Lake Greifensee discharges into the River Glatt, an affluent of the River Rhine. To compare the situation in a lake and a stream, ten samples from the River Rhine at Weil am Rhein were taken during a discharge event in September 2006. In addition, samples from different groundwater sampling monitoring stations in Switzerland were taken to assess the occurrence in groundwater. All sampling sites are depicted in Fig. 1.

Raw samples were transferred to $500-\mathrm{mL}$ polyethylene bottles and stored in the dark at $-20{ }^{\circ} \mathrm{C}$ until analysis. In order to evaluate analyte losses during storage and defrosting, different samples were spiked to $60 \mathrm{ng} / \mathrm{L}$ before freezing; no significant losses were detected.

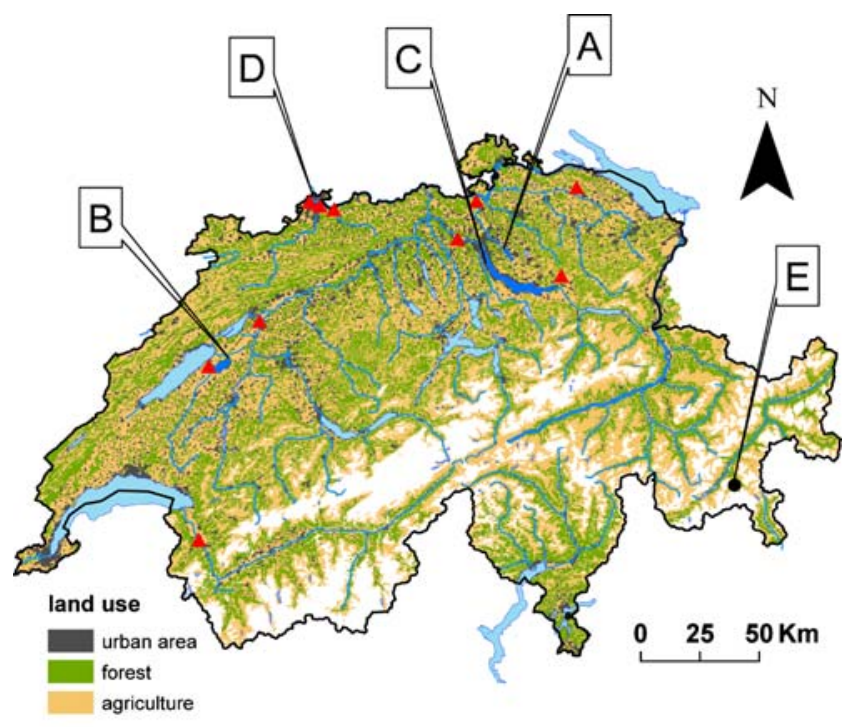

은 2007 swisstopo

Fig. 1 Sampling locations in Switzerland: Lake Greifensee $(A)$, Lake Murtensee $(B)$ and Lake Zurich $(C)$, as well as groundwater sampling sites at different places in the Swiss plateau (red triangles) and the sampling site on the River Rhine $(D)$. Surface water samples from the remote alpine region of Val Roseg $(E)$ were taken for the validation study

\section{Derivatization}

A sample aliquot of $80 \mathrm{~mL}$ was transferred to a glass bottle. In order to eliminate possible interactions of glyphosate with matrix components, the sample solution was acidified with $6 \mathrm{M}$ $\mathrm{HCl}$ to $\mathrm{pH} 1$ according to the procedure described in [21]. To maximize the dissociation of possible analyte-cation complexes (see "Results and discussion") the $\mathrm{pH} 1$ was maintained for one hour. Subsequently, the sample was spiked with $100 \mu \mathrm{L}$ of the internal standard mixture solution and neutralized with $6 \mathrm{M} \mathrm{KOH}$. Ten milliliters of borate buffer and $10 \mathrm{~mL}$ of FMOC-Cl stock solution were added, resulting in an FMOC-Cl concentration of $650 \mu \mathrm{M}$. The bottle was shaken vigorously. After two hours the reaction was stopped by acidifying the solution to approximately $\mathrm{pH} 3$ by adding $1 \mathrm{~mL}$ of formic acid. The solution was filtered with a $250-\mathrm{mL}$ bottle-top filtration unit, using a $0.45 \mu \mathrm{m}$ regenerated cellulose membrane filter (Milian, Geneva, Switzerland). The recovery of the filtration step was checked for different samples; no significant losses occurred during filtration.

The derivatized sample was diluted with $100 \mathrm{~mL}$ of water; $4 \mathrm{~mL}$ of the EDTA solution were added.

\section{SPE procedure}

Strata-X sorbent cartridges $(33 \mu \mathrm{m}, 200 \mathrm{mg}$; Phenomenex, Brechbühler AG, Schlieren, Switzerland) were used on a 12-fold vacuum extraction box (Supelco, Bellefonte, PA, USA). Cartridges were conditioned with $5 \mathrm{~mL}$ of $\mathrm{MeOH}$ 
followed by $5 \mathrm{~mL}$ of $0.1 \%$ formic acid. The derivatized samples were extracted at a flow rate of approximately $2.5 \mathrm{~mL} / \mathrm{min}$. The excess of water was removed by opening the valves and letting air pass through the cartridges for approximately $30 \mathrm{~min}$. To remove the derivatization byproducts, the cartridges were rinsed with $3.5 \mathrm{~mL}$ of dichloromethane and again dried with air for another $30 \mathrm{~min}$. The analytes were eluted with $9 \mathrm{~mL}$ of $\mathrm{MeOH}$ without using vacuum. The extracts were collected in conical bottom glass vessels (Supelco, Bellefonte, PA, USA). The $\mathrm{MeOH}$ aliquots were reduced to approximately $50 \mu \mathrm{L}$ by a gentle flow of nitrogen gas at $50{ }^{\circ} \mathrm{C}$. The extracts were transferred to $2-\mathrm{mL}$ amber glass vials with inserts and the volume was reconstituted with $5 \mathrm{mM} \mathrm{NH}_{4}$-acetate (pH 9) to approximately $250 \mu \mathrm{L}$ in order to obtain the initial mobile phase conditions for the injection into the LC-MS/MS.

Liquid chromatography and mass spectrometry

The injection volume for LC-MS/MS analysis was $20 \mu \mathrm{L}$. An XBridge column (Waters, C18, $3.5 \mu \mathrm{m}, 30 \mathrm{~mm} \times 2 \mathrm{~mm}$ i.d., PEEK-lined) was used for analyte separation. The mobile phase was composed of water buffered with $5 \mathrm{mM}$ ammonium acetate of $\mathrm{pH} 9$ (solvent $\mathrm{A}$ ) and $\mathrm{MeOH}$ (solvent $\mathrm{B}$ ). The LC gradient for the separation was: from 0 to $3 \mathrm{~min}$, a linear increase of $\mathrm{B}$ from 10 to $25 \%$; isocratic from 3 to $6 \min (75 \% \mathrm{~A}: 25 \% \mathrm{~B})$; from 6 to $15 \mathrm{~min}$, a linear increase of B from 25 to $90 \%$; isocratic $90 \%$ B from 15 to $17 \mathrm{~min}$. Initial conditions were reestablished in $1 \mathrm{~min}$ and the column was re-equilibrated for $7 \mathrm{~min}$, resulting in a total run time of $25 \mathrm{~min}$. The flow rate was $0.2 \mathrm{~mL} / \mathrm{min}$ and the column temperature was $30{ }^{\circ} \mathrm{C}$.

The target substances were detected with a triple quadrupole mass spectrometer, an API 4000 (Applied Biosystems, Foster City, CA, USA), which was operated with a HPLC system consisting of a quaternary pump, a degasser and an autosampler (all Agilent 1100, Agilent
Technologies, Waldbronn, Germany). The instrument was equipped with electrospray ionization and was calibrated using a 1,3,6-polytyrosine solution. It was operated with unit mass resolution (0.7 u FWHM). Optimization of ionization and fragmentation conditions for the analytes was obtained by loop injection $(20 \mu \mathrm{L})$ of $0.1 \mathrm{~g} / \mathrm{L}$ solutions of the individual FMOC-derivatized analytes. After selecting predominant precursor ions, product scans were used to identify main fragments. Instrument parameters like collision energies or declustering potential were optimized by multiple injections in the selected reaction monitoring (SRM) mode. The instrument parameters were: spray voltage $-4500 \mathrm{~V}$, temperature $390{ }^{\circ} \mathrm{C}$, collision gas 11 (arbitrary units), curtain gas 30 (arbitrary units). Details of the substance-specific parameters for the ionization and detection of the FMOC-derivatized analytes and isotopelabeled standards are given in Table 1.

Optimization of the derivatization

The optimum settings to achieve a complete reaction were elaborated. The reaction time, the ratio of $\mathrm{ACN}$ to water and the concentration of FMOC-Cl were all varied. All of the experiments were performed at room temperature and the solution was buffered with sodium tetraborate at $\mathrm{pH}$ 9. The initial concentrations of glyphosate, AMPA and glufosinate were adjusted to $2.5 \mu \mathrm{M}$. A second solution was prepared in a similar manner in order to quantify the reaction yield. Instead of adding the mixture solution of the nonderivatized substances, the derivatization solution was spiked with an equivalent amount of "Mix-FMOC" directly before measurement. This procedure takes into account the possible matrix effects that may change during the reaction. An aliquot was taken from the solutions every $30 \mathrm{~min}$. The aliquot was immediately filtered (regenerated cellulose, $0.45 \mu \mathrm{m}$, Schleicher \& Schuell) and quantified by direct infusion into the tandem mass spectrometer.

Table 1 Precursor ions ([M H] ), main product ions (quantifier), secondary product ions (qualifier) and corresponding declustering potential and collision energy

\begin{tabular}{|c|c|c|c|c|c|}
\hline Analyte & Precursor ion $m / z$ & Product ion $\mathrm{m} / \mathrm{z}$ & $\begin{array}{l}\text { Quantifier (Q) or } \\
\text { qualifier (q) }\end{array}$ & Declustering potential $V$ & Collision energy $V$ \\
\hline \multirow[t]{2}{*}{ Glyphosate FMOC } & 390.1 & 168.0 & Q & 39.0 & 16.0 \\
\hline & 390.1 & 150.0 & $\mathrm{q}$ & 39.0 & 35.0 \\
\hline \multirow[t]{2}{*}{ AMPA FMOC } & 332.1 & 110.0 & $\mathrm{Q}$ & 39.0 & 11.0 \\
\hline & 332.1 & 136.0 & $\mathrm{q}$ & 39.0 & 21.0 \\
\hline \multirow[t]{2}{*}{ Glufosinate FMOC* } & 402.1 & 180.0 & Q & 45.0 & 13.0 \\
\hline & 402.1 & 206.0 & $\mathrm{q}$ & 45.0 & 20.0 \\
\hline \multirow[t]{2}{*}{$1,2{ }^{13} \mathrm{C}_{2}{ }^{15} \mathrm{~N}$ Glyphosate FMOC } & 393.1 & 171.0 & $\mathrm{Q}$ & 39.0 & 16.0 \\
\hline & 393.1 & 153.0 & $\mathrm{q}$ & 39.0 & 35.0 \\
\hline \multirow[t]{2}{*}{${ }^{13} \mathrm{C}{ }^{15} \mathrm{~N}$ AMPA FMOC } & 334.1 & 112.0 & $\mathrm{Q}$ & 39.0 & 11.0 \\
\hline & 334.1 & 138.0 & $\mathrm{q}$ & 39.0 & 21.0 \\
\hline
\end{tabular}

*With ${ }^{13} \mathrm{C}^{15} \mathrm{~N}$ AMPA FMOC used as internal standard 
Since other amines may occur in surface water which can react with $\mathrm{FMOC}-\mathrm{Cl}$ and give the same product ions in MS/MS, the yields in environmental water samples were also determined by a more specific LC-MS/MS analysis besides direct infusion.

\section{Optimization of the solid-phase extraction}

To find the best SPE conditions, the breakthrough and the absolute extraction recovery were evaluated in nanopure water for different settings of sorbent amount, sample amount, and content of ACN. To determine the absolute extraction recovery, derivatized sample solutions were spiked with "Mix-FMOC" to $650 \mathrm{ng} / \mathrm{L}$ and extracted. The resulting concentration of the extract was compared to the theoretical concentration for a recovery of $100 \%$. Since no FMOC isotope-labeled standards were available, the quantification of the FMOC-derivates in the SPE extracts was carried out by means of standard additions. For this purpose $150 \mathrm{ng}, 300 \mathrm{ng}$ and $450 \mathrm{ng}$ of analytes were added to three aliquots of the evaporated eluate by spiking them with "Mix-FMOC."

The breakthrough was checked using a stacked cartridge approach (one on top of the other) and by determining the absolute extraction recoveries of both cartridges.

The absolute extraction recovery for the optimized SPE setup was ascertained in surface water and groundwater.

\section{Performance characteristics}

\section{Validation parameters}

The limit of detection (LOD) and the limit of quantification (LOQ) were determined in different matrices (nanopure water, groundwater and surface water) based on ISO 11843 [23]. The sample solutions were spiked at the following concentration levels: 1, 2, 4, 6, 8, $10 \mathrm{ng} / \mathrm{L}$. In groundwater and surface water the accuracy of the method was determined via three replicates by spiking the sample solution to a concentration of $2 \mathrm{ng} / \mathrm{L}$. The ratio between the quantified amount (background subtraction, if necessary) and the spiked amount is defined as the relative recovery. To assess the ionization efficiency, extracted eluates of different matrices (nanopure water, groundwater and surface water) were spiked with different amounts of "Mix-FMOC" and the slope of the calibration curve in the matrices was compared to the slope in nanopure water.

\section{Quantification of environmental samples and quality assurance}

For sample quantification, calibration curves from spiked nanopure water standards with concentration levels of 0.5 , $1,2,4,6,8,10,25,50,100,250$ and $500 \mathrm{ng} / \mathrm{L}$ were used.
The standard mixture solution "Mix-STD" was added directly after the addition of the ILS. The calibration standards were otherwise treated like normal samples. The calibration curve was obtained by plotting the ratio of the analyte area to the ILS area against the known standard concentration. The corresponding ILSs were used for glyphosate and AMPA. Glufosinate was quantified with the ILS of AMPA. All extracted calibration standards were measured at the beginning and the end of a sequence. While the first measurement of the standards was used to build up the calibration curve, the second measurement served as quality control. For quality assurance, fortified environmental samples were checked for recovery in each sequence. In order to monitor the background concentrations or possible carryover while measuring samples, double-blank (nanopure water without analytes or internal standard solution) and blank samples (without analytes but with internal standard solution) were extracted in every sequence.

\section{Results and discussion}

\section{Derivatization}

\section{Amount of acetonitrile}

Since FMOC-Cl is almost insoluble in water, the derivatization solution has to contain a certain amount of an organic solvent like acetone or acetonitrile. Many different levels of acetonitrile (between $12 \%$ and $50 \%$ ) are mentioned in the literature. Nedelkoska and Low [16] for example proposed an acetonitrile:water ratio of $1: 1$ to achieve optimum yield. However, for enrichment on a reversed-phase material, samples with a high content of organic solvent must be considerably diluted. To increase the original sample volume in order to get a better sensitivity, the sample should not have to be diluted to a great extent after derivatization. In order to minimize the dilution factor, the addition of acetonitrile to the derivatization solution should be kept as low as possible.

Furthermore, data in the literature regarding the reaction time differ greatly. In some cases the reaction took $30 \mathrm{~s}$ [24], whereas in others it was terminated after half an hour $[20,25]$ or even only after several hours ("overnight") $[10,11]$.

In order to obtain a fast and complete reaction with FMOC-Cl, the yield and the kinetics of the reaction of FMOC-Cl with glyphosate, AMPA and glufosinate in different matrices were analyzed.

To estimate the lowest content of $\mathrm{ACN}$ required for a complete reaction, experiments at different $\mathrm{ACN}$ contents $(1 \%, 5 \%, 10 \% \mathrm{v} / \mathrm{v})$ were carried out in nanopure water. After 
two hours at $1 \% \mathrm{ACN}$ the reaction yields were between 15 and $60 \%$ for glyphosate, AMPA and glufosinate. After six hours the yields did not increase significantly. The yields at $5 \%$ ACN were higher (between 50 and $95 \%$ ), but a complete transformation (100 and 115\%) was only accomplished for all three compounds at $10 \%$ ACN (Fig. 2). The influence of the sample matrix was analyzed as well. The transformation yield in water from Lake Greifensee at $10 \% \mathrm{ACN}$ was also above $90 \%$ for glyphosate, AMPA and glufosinate after a reaction time of $2 \mathrm{~h}$.

\section{Concentration of $\mathrm{FMOC} \mathrm{Cl}$}

Since FMOC-Cl reacts not only with the analytes but also with other amines, amino acids and also water, forming FMOC-OH, an excess of FMOC-Cl must be added to the sample. Since by-products are likely to interfere with the subsequent steps of the sample preparation, their formation ought to be minimized. One way to accomplish this goal is to decrease the initial FMOC-Cl concentration. The influence of the concentration of FMOC-Cl on the reaction yield was therefore studied. Reported values are between $250 \mu \mathrm{M}[16]$ and 10,000 $\mu \mathrm{M}$ [26]. Experiments performed at several concentration levels $(650 \mu \mathrm{M}, 325 \mu \mathrm{M}, 130 \mu \mathrm{M}$, $65 \mu \mathrm{M}$ ) in different matrices (nanopure water, lake water, waste water) at an $\mathrm{ACN}$ content of $10 \%$ were conducted. Measured values for glyphosate are shown in Fig. 3. AMPA and glufosinate showed comparable reaction rates and yields.

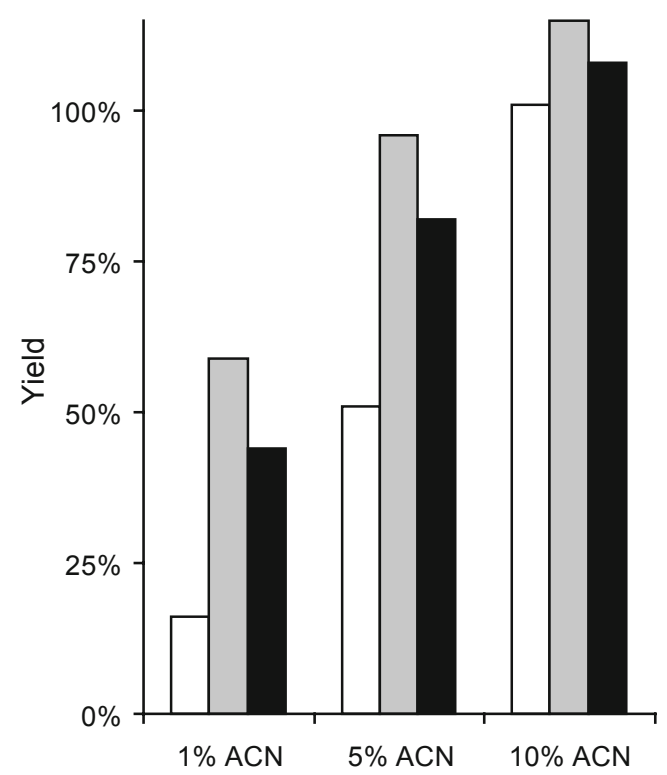

Fig. 2 Derivatization yield in relation to the amount of acetonitrile in nanopure water after a reaction time of $2 \mathrm{~h}$. The relative standard error of repeated analysis $(N=5)$ of one parameter setting was $9.8 \%$ for glyphosate, $2.7 \%$ for AMPA and $5.1 \%$ for glufosinate. White bars, glyphosate; gray bars, AMPA; black bars, glufosinate

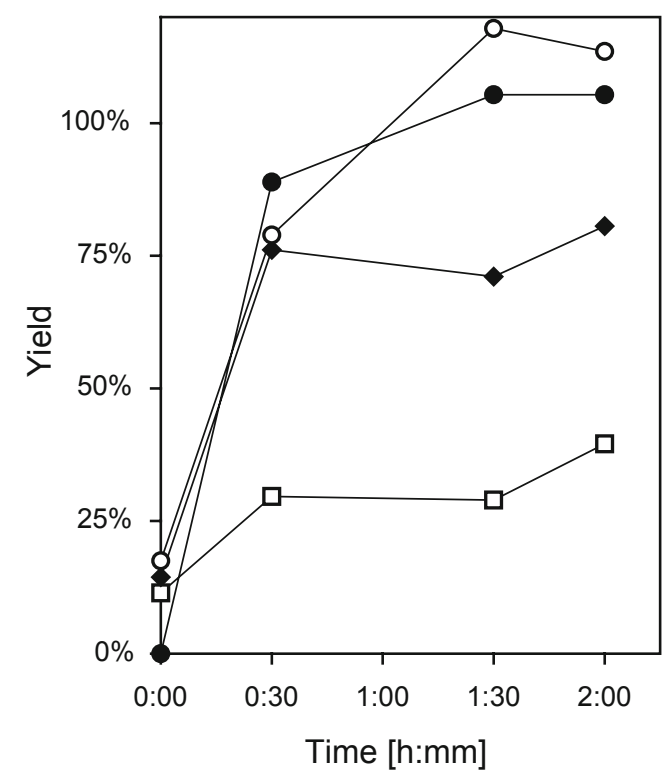

Fig. 3 Influence of the FMOC $\mathrm{Cl}$ concentration on the absolute yield of the reaction of glyphosate with $\mathrm{FMOC} \mathrm{Cl}$ in nanopure water at an ACN content of $10 \%$. The relative standard error of repeated analysis $(N=3)$ of one parameter setting was $6.7 \%$. Squares, $65 \mu \mathrm{M}$; diamonds, $130 \mu \mathrm{M}$; open circles, $325 \mu \mathrm{M}$; filled circles, $650 \mu \mathrm{M}$

Although in nanopure water an FMOC-Cl concentration of $325 \mu \mathrm{M}$ was sufficient, in environmental samples such as lake water samples, the concentration had to be increased to $650 \mu \mathrm{M}$ in order to achieve the complete reaction. This was confirmed by measurements of different environmental matrices (groundwater, river water, lake water). The reaction was even nearly complete in effluent samples from a wastewater treatment plant (glyphosate 64\%, AMPA $90 \%$, glufosinate $102 \%$ ). In environmental water samples an optimum yield was thus attained at room temperature after 2 hours at a FMOC-Cl concentration of $650 \mu \mathrm{M}$ and an $\mathrm{ACN}$ content of $10 \%$.

\section{Addition of EDTA}

As shown in detail by Freuze et al. [22], multivalent cations such as iron, copper and calcium form stable complexes with glyphosate and AMPA which are not derivatized to the corresponding FMOC derivate. Complexation occurs in particular in natural water samples with low organic carbon content and considerable amounts of alkaline, alkaline earth and metal cations, which is the case for many groundwaters. To be able to analyze the free as well as the complexed glyphosate and AMPA in natural water samples, Ibañez and coworkers [21] proposed a procedure which includes acidification of the sample to $\mathrm{pH} 1$ and subsequent addition of the ILS. If recomplexation, which is probably very slow according to [21], occurs after internal standard spiking, this effect is compensated for by using the internal standard. Nevertheless, significant complex reformation by 
the FMOC derivates and cations during the derivatization could result in reduced sensitivity. As pointed out in [22], metal ions with high complex formation constants can also build stable complexes at $\mathrm{pH} 9$, which is used in the derivatization solution.

To investigate this effect, $80 \mathrm{~mL}$ of nanopure water were spiked with an iron(II) solution to an iron(II) concentration of $50 \mathrm{mg} / \mathrm{L}$. The solution was then derivatized as described in the "Experimental" section. After the derivatization the solution was spiked with "Mix-FMOC" to a concentration of $650 \mathrm{ng} / \mathrm{L}$. The recovery of the spiked analyte in the solution analyzed with the developed SPE-LC- MS/MS method was less than $10 \%$. The concentrations were determined by standard addition. The same experimental setup with the addition of $4 \mathrm{~mL}$ of the EDTA solution to the derivatized solution resulted in a recovery of $85 \%$. This shows that during and after the derivatization step the complexation of FMOC derivates of glyphosate and AMPA with cations, most probably at the phosphonic acid group, can significantly diminish the sensitivity of the method. The experiments done with iron(II) confirm the statement of Freuze et al. that EDTA is thermodynamically able to dissociate complexes of glyphosate and AMPA at pH 9.2. Although experiments were not conducted for all multivalent cations, a combination of acidification to $\mathrm{pH} 1$ prior to derivatization and the addition of EDTA after the two-hour derivatization are needed for a sensitive and reliable quantification of glyposate and AMPA in natural waters.
Therefore, both procedures were implemented to avoid complexation in the final method. The extent to which complexation is an important issue for the determination of glufosinate, with a phosphinic acid group, is not clear.

\section{Solid-phase extraction}

Several different SPE materials that are suitable for the enrichment of glyphosate-FMOC were tested. Functionalized copolymeric SPE phases like Oasis HLB or Strata-X have proven valuable for the enrichment of the derivatized analytes [27]. The recoveries with different proportions of $\mathrm{ACN}$, different amounts of the solid phase material as well as various sample volumes were studied for Strata-X.

\section{Breakthrough}

Factors influencing breakthrough are the total volume of the sample, the content of the organic solvent $\mathrm{ACN}$, and the amount of sorbent. The lowest ACN level needed for derivatization had been found to be $10 \%$. However, at this ACN content breakthrough occurred on a $60 \mathrm{mg}$ cartridge, as indicated by the trapping of $29 \%$ of the glyphosate and $23 \%$ of the AMPA on the second cartridge (Fig. 4). Decreasing the sample solution from $100 \mathrm{~mL}$ to $50 \mathrm{~mL}$ at $60 \mathrm{mg}$ and $10 \% \mathrm{ACN}$ was not sufficient to avoid breakthrough completely. The dilution of the original solution with nanopure water to $200 \mathrm{~mL}$, resulting in an

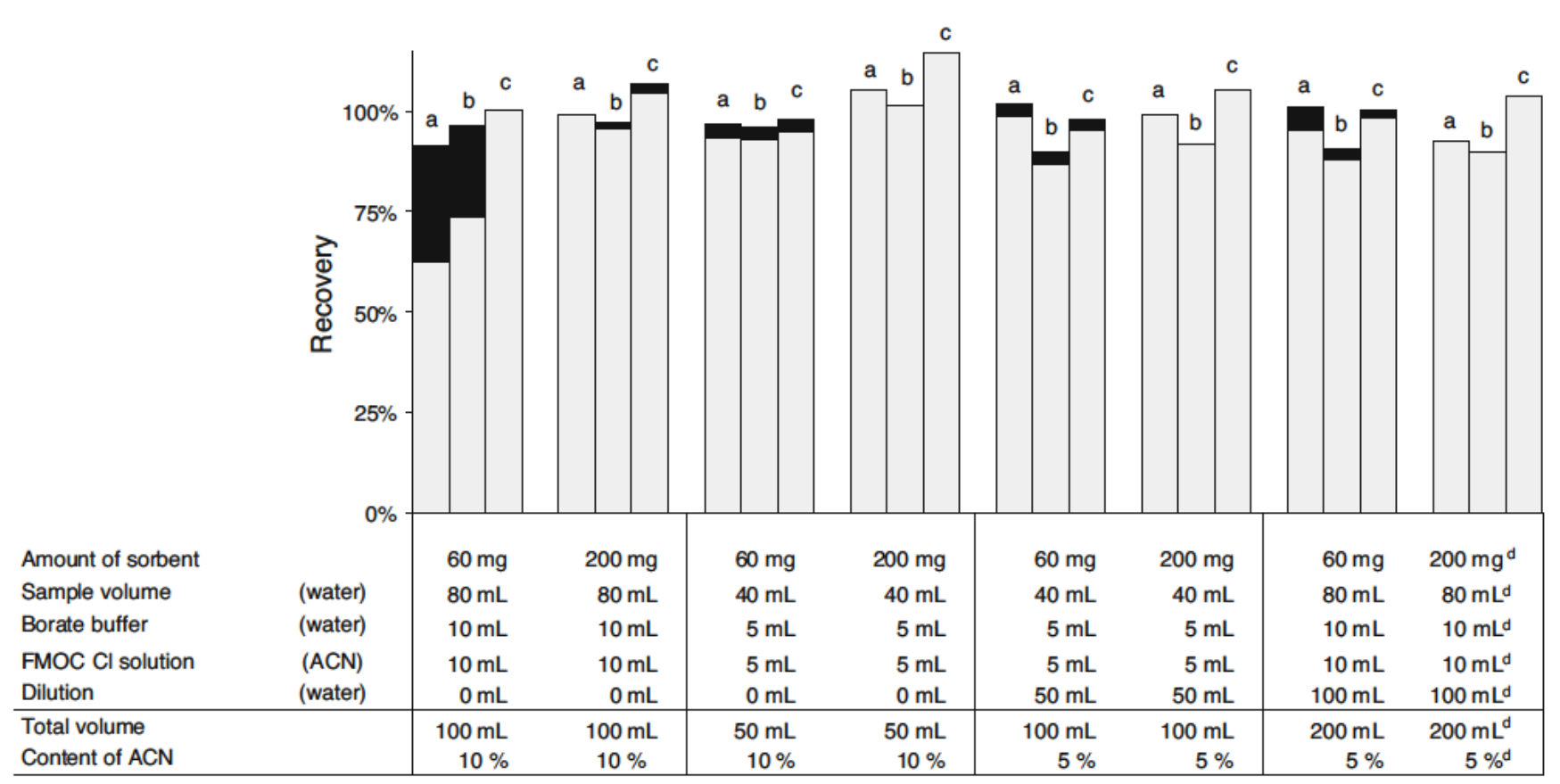

Fig. 4 Absolute extraction recovery and breakthrough of FMOC derivates of glyphosate $(a)$, AMPA $(b)$ and glufosinate $(c)$ in nanopure water. The relative standard error of repeated analysis $(N=3)$ of one

parameter setting was $4.9 \%$ for glyphosate, $7.5 \%$ for AMPA and $4.1 \%$ for glufosinate. Shaded bars, bottom cartridge; plain bars, top cartridge. ${ }^{\mathrm{d}}$ selected settings 
ACN content of 5\%, still resulted in breakthrough at $60 \mathrm{mg}$, whereas at $200 \mathrm{mg}$ of sorbent all three analytes were retained on the first cartridge, even with $10 \% \mathrm{ACN}$. However, to be on the safe side when analyzing environmental matrices such as surface waters or groundwaters, all samples were diluted with $100 \mathrm{~mL}$ nanopure water to a total amount of $200 \mathrm{~mL}$ and an ACN content of $5 \%$.

\section{Rinsing step and absolute extraction recovery}

ACN, hexane, dichloromethane were compared in terms of their abilities to pre-elute FMOC-OH and other uncharged, lipophilic by-products.

A derivatized and filtrated sample solution was spiked with "Mix-FMOC" to a concentration of $650 \mathrm{ng} / \mathrm{L}$ and enriched on a cartridge with $200 \mathrm{mg}$ sorbent. The cartridges were then rinsed with each rinsing solvent and eluted with $\mathrm{MeOH}$. The rinsing solution and the eluate were collected in reaction vessels. The applicability of the rinsing solution was assessed by adding water to the reaction vessel to see if the water-insoluble FMOC-OH precipitated. The presence of FMOC-OH was further qualitatively assessed by measurements with HPLC-DAD. Additionally, the absolute extraction recoveries of the analytes in the eluate were determined.

Hexane did not remove the FMOC-OH. ACN was able to elute the FMOC-OH; however, the analytes were partially eluted as well. Only dichloromethane eluted a considerable amount of by-products. The analytes remained on the cartridge, as indicated by absolute extraction recoveries of $97 \pm 4 \%$, (glyphosate), 92 $\pm 3 \%$ (AMPA) and $105 \pm 1 \%$ (glufosinate) for nanopure water. The absolute extraction recoveries in groundwater were $68 \pm 1 \%$ for glyphosate, $67 \pm 6 \%$ for AMPA and $85 \pm 6 \%$ for glufosinate. In surface water, absolute extraction recoveries of $88 \pm 10 \%$ for glyphosate, $81 \pm 4 \%$ for AMPA and $88 \pm 4 \%$ for glufosinate were obtained. Polar aprotic solvents like dichloromethane and ACN are thus suitable for removing FMOC-OH from the polymeric Strata-X sorbent, while elution of the analytes requires a polar protic solvent like $\mathrm{MeOH}$. The rinsing step only leads to a minor reduction in the absolute extraction recovery.

\section{Chromatography}

\section{Sorption to capillary tubings and background noise}

In order to improve the performance of the liquid chromatography various mobile phases were tested. To achieve a chromatogram with good resolution as well as to minimize background noise, two buffers (ammonium acetate and ammonium carbonate) at different concentrations $(5 \mathrm{mM}, 20 \mathrm{mM})$ and several $\mathrm{pH}$ values $(8,9$ and 10$)$ were compared. Absolute peak areas decreased with increasing buffer concentration and with increasing $\mathrm{pH}$. Since background noise decreased with increasing $\mathrm{pH}$ as well, the best sensitivity was obtained at $\mathrm{pH} 9$ due to an optimal signal-to-noise ratio.

Background noise is probably a consequence of analytes sorbing to the HPLC capillaries, which are subsequently released during further analytical runs. The choice of material used for the capillaries was thus considered to be critical. A possible sorption was evaluated by comparing peak areas of standard solutions flowing through different capillary materials, i.e., polyetheretherketone (PEEK), fused silica, nickel, titanium, steel and passivated steel. The standards were prepared by fortifying an initial HPLCgradient solution with "Mix-FMOC" to a concentration of $65 \mu \mathrm{g} / \mathrm{L}$. These were injected into a $20 \mu \mathrm{L}$ loop and a capillary made from the same material. Glyphosate-FMOC and AMPA-FMOC interacted strongly with the steel surface, likely via complexes of the phosphonic acid moiety with the capillary surface, which resulted in considerable peak tailing. Glufosinate-FMOC was not affected by the steel surface, since the phosphinic acid moiety does not form Fe complexes. Passivating the steel capillaries using nitric acid did not lead to the expected improvement in peak shape and area. Titanium and nickel capillaries were also unsuitable for HPLC, as both led to similar peak shapes to those seen for steel. Fused silica and PEEK capillaries both showed low sorption with low background signal at $\mathrm{pH}$ values above 8 . Due to its easy handling (flexible, pressurestable connectors), PEEK was considered the most suitable material for capillary and column hardware when mobile phases with basic $\mathrm{pH}$ values are used.

\section{Method validation}

\section{Limits of detection (LOD) and quantification (LOQ)}

LOD and LOQ determined from the calibration function based on ISO 11843 are shown in Table 2. The values in the three matrices were all at the low ng/L level and show that the detection of glyphosate is even possible below a level of $1 \mathrm{ng} / \mathrm{L}$. The LOD is thus comparable to methods currently used for the determination of other pesticides in environmental samples. The concentrations determined by using the main product ion (quantifier) were verified by considering the area ratio of the secondary product ion (qualifier) to the quantifier compared to the area ratio of the standards in nanopure water. The ratio differed by less than $12 \%$, indicating good agreement between the two transitions.

A low but constant background value was observed for all three analytes with an absolute peak area that was slightly lower than the peak area of the LOD in Table 2. The LOD and LOQ could therefore also be determined by using the variation of this blank value. The LOD is thereby 
Table 2 Limits of detection (LOD) and limits of quantification (LOQ) based on ISO 11843, and relative recoveries (rel. rec.) of spiked samples (2 ng/L, $N=3$ ) for different matrices

\begin{tabular}{lllll}
\hline & & Glyphosate & AMPA & Glufosinate \\
\hline Nanopure water & LOD & $0.4 \mathrm{ng} / \mathrm{L}$ & $0.4 \mathrm{ng} / \mathrm{L}$ & $0.5 \mathrm{ng} / \mathrm{L}$ \\
& LOQ & $1.6 \mathrm{ng} / \mathrm{L}$ & $1.6 \mathrm{ng} / \mathrm{L}$ & $1.8 \mathrm{ng} / \mathrm{L}$ \\
Groundwater & LOD & $0.5 \mathrm{ng} / \mathrm{L}$ & $0.1 \mathrm{ng} / \mathrm{L}$ & $0.9 \mathrm{ng} / \mathrm{L}$ \\
& LOQ & $1.8 \mathrm{ng} / \mathrm{L}$ & $0.5 \mathrm{ng} / \mathrm{L}$ & $3.4 \mathrm{ng} / \mathrm{L}$ \\
Surface water & Rel. rec. & $103 \pm 10 \%$ & $103 \pm 10 \%$ & $91 \pm 6 \%$ \\
& LOD & $0.2 \mathrm{ng} / \mathrm{L}$ & $0.2 \mathrm{ng} / \mathrm{L}$ & $0.6 \mathrm{ng} / \mathrm{L}$ \\
& LOQ & $0.7 \mathrm{ng} / \mathrm{L}$ & $0.8 \mathrm{ng} / \mathrm{L}$ & $2.3 \mathrm{ng} / \mathrm{L}$ \\
& Rel. rec. & $97 \pm 9 \%$ & $103 \pm 2 \%$ & $107 \pm 12 \%$ \\
\hline
\end{tabular}

considered the average of the blank value plus three times the standard deviation of the blank value. The LOQ is the average value plus ten times the standard deviation. The obtained values were comparable to those determined from the calibration function. Although no ILS is commercially available for glufosinate and thus the ILS of AMPA had to be used, the LOD and LOQ of glufosinate are only a little higher than those of glyphosate and AMPA.

Chromatograms for both transitions of the analytes in a surface water sample from Val Roseg spiked at concentrations of $1 \mathrm{ng} / \mathrm{L}$ and $10 \mathrm{ng} / \mathrm{L}$ are shown in Fig. 5a and b.

\section{Linearity}

Calibration curves were linear according to ISO 8466-1 [28] over the entire calibration range from 0.5 to $500 \mathrm{ng} / \mathrm{L}$. To quantify the environmental samples the calibration range was usually adjusted to a concentration range of 0.5 to $50 \mathrm{ng} / \mathrm{L}$. The regression equations, with slope $b$, intercept $a$, standard error of slope $s_{\mathrm{b}}$, standard error of intercept $s_{\mathrm{a}}$ and correlation coefficient $r^{2}$ were as follows: glyphosate $b \pm s_{\mathrm{b}}$ $0.02512 \pm 0.00051, a \pm s_{\mathrm{a}} 0.05555 \pm 0.00318, r^{2} \quad 0.9983$; AMPA $b \pm s_{\mathrm{b}} 0.04710 \pm 0.00092, a \pm s_{\mathrm{a}} 0.03714 \pm 0.00571, r^{2}$ 0.9985; glufosinate $b \pm s_{\mathrm{b}} 0.06191 \pm 0.00126, a \pm s_{\mathrm{a}} 0.00785 \pm$ $0.00873, r^{2} 0.9983$.

\section{Precision}

The day-to-day variations of the glyphosate and AMPA were investigated with replicate extractions $(N=3)$ of aliquots of a sample from Lake Zurich ( $5 \mathrm{ng} / \mathrm{L}$ glyphosate, $15 \mathrm{ng} / \mathrm{L}$ AMPA) and a sample from Lake Greifensee (44 ng/L glyphosate, $58 \mathrm{ng} / \mathrm{L}$ AMPA). The relative standard deviations (RSD) of the average concentrations in Lake Zurich were $11 \%$ and $4 \%$ for glyphosate and AMPA, respectively. The RSDs for the sample from Lake Greifensee were $8 \%$ and $5 \%$ for glyphosate and AMPA, respectively. In Fig. $5 \mathrm{c}$ the chromatograms for the sample from Lake Zurich are shown.

\section{Accuracy}

The accuracy was determined as the recovery of the spiked analyte relative to the internal standard. Environmental samples (groundwater, surface water) were spiked at a concentration level of $2 \mathrm{ng} / \mathrm{L}$. Relative recoveries were in the range of $91-107 \%$ for all three substances (Table 2).

\section{Ionization efficiency}

The slopes of the calibration curves based on absolute peak values in the different matrices did not differ by more than $11 \%$. Thus, ionization was not significantly affected by suppression or enhancement, confirming the efficient removal of derivatization by-products during the SPE rinsing step.

\section{Environmental samples}

Samples of groundwater, river and lake water were collected at the Swiss plateau, a region with high agricultural activity, and analyzed for glyphosate, AMPA and glufosinate. One sequence included 12 samples, 2-4 blanks, a calibration curve in the range of $0.5-500 \mathrm{ng} / \mathrm{L}$ and a quality control sample for each matrix (groundwater and surface water) spiked at a level of $50 \mathrm{ng} / \mathrm{L}$.

Depth profiles of Lake Murtensee and of Lake Greifensee as well as samples of the main tributaries were analyzed. In summer both lakes exhibit a distinct stratification due to a sharp density gradient that divides the water body into a warm upper layer (epilimnion) and a cold bottom layer (hypolimnion). The epilimnion and the hypolimnion can be regarded as separate but well-mixed boxes, and the concentrations of herbicides within the layers are expected to be homogeneous.

In both lakes the concentrations of all target compounds were low or below the limit of quantification in the epilimnion (Fig. 6). In the hypolimnion, however, concentrations of glyphosate were around $15 \mathrm{ng} / \mathrm{L}$ (Lake Murtensee) and $35 \mathrm{ng} / \mathrm{L}$ (Lake Greifensee). The concentrations of AMPA were slightly higher in both lakes, with levels around $60 \mathrm{ng} / \mathrm{L}$. In the tributaries of Lake Greifensee, the concentrations of glyphosate and of AMPA ranged from 30 to $390 \mathrm{ng} / \mathrm{L}$ and from 100 to $170 \mathrm{ng} / \mathrm{L}$, respectively. Glufosinate did not exceed the detection limit in any of the analyzed samples. In the main tributary of Lake Murtensee, glyphosate and AMPA concentrations were at $100 \mathrm{ng} / \mathrm{L}$ and $290 \mathrm{ng} / \mathrm{L}$, respectively. Considering the input loads into the lake and the water residence time, the observed dissipation of glyphosate and AMPA in the epilimnion could possibly be explained by degradation or sorption processes.

As the concentrations of glyphosate in Lake Greifensee were in the same range or even higher than those in Lake Murtensee, urban sources in the densely populated 

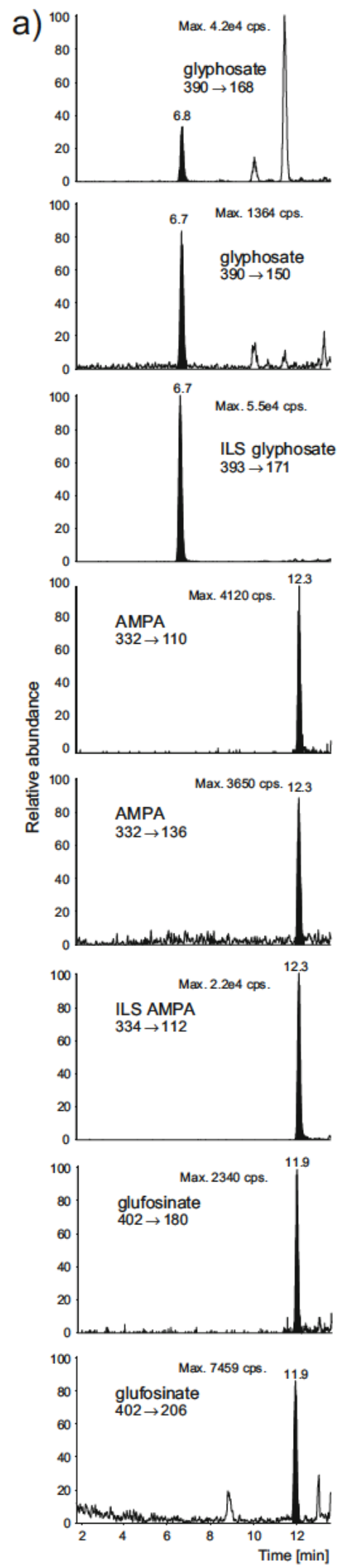

Fig. 5 LC MS/MS chromatograms for spiked surface water samples (Val Roseg) with concentrations of $1 \mathrm{ng} / \mathrm{L}$ (a) and $10 \mathrm{ng} / \mathrm{L}$ (b) of glyphosate, AMPA and glufosinate, and a sample from Lake Zurich
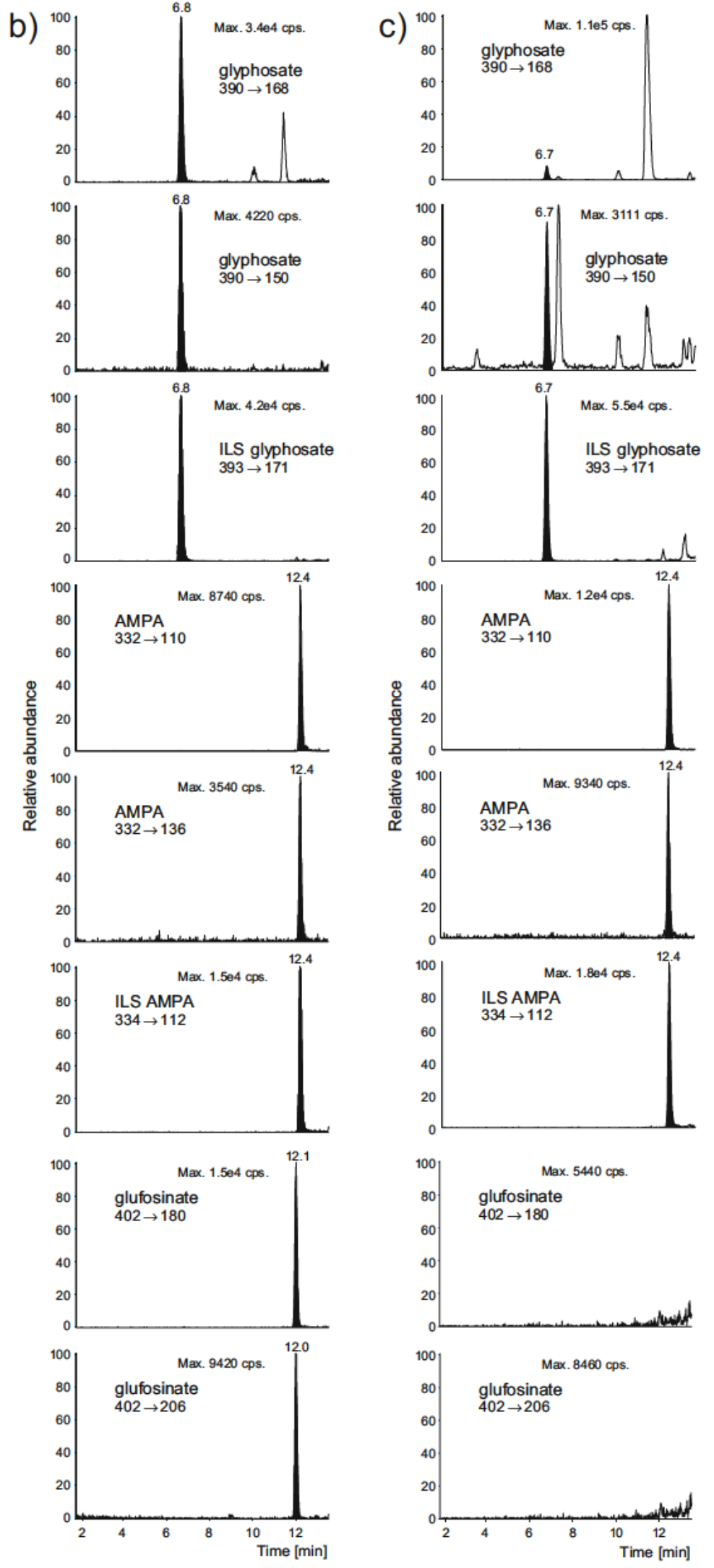

with a concentration level of $5 \mathrm{ng} / \mathrm{L}$ of glyphosate and $15 \mathrm{ng} / \mathrm{L}$ of AMPA (c). For each analyte both transitions and the quantifier of the corresponding internal standard is shown 

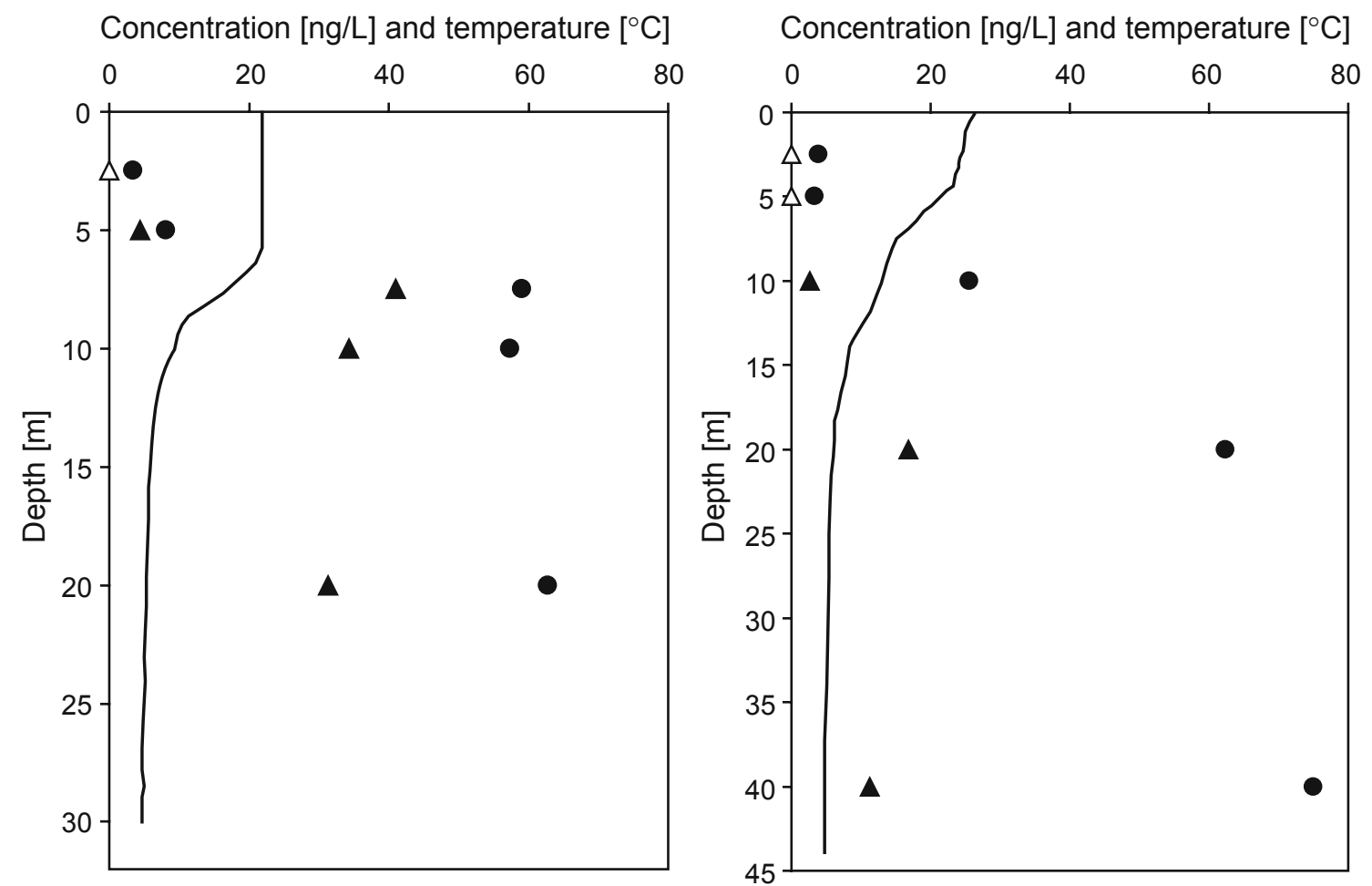

Fig. 6 Vertical concentration profiles of glyphosate and AMPA in Lake Greifensee (left) and Lake Murtensee (right) in summer 2006. Line, water temperature; filled triangles, glyphosate; circles, AMPA; open triangles, glyphosate levels below the limit of quantification

Greifensee catchment probably contribute a considerable amount of the glyphosate. The importance of the contribution of treated wastewater to the glyphosate load of surface water was also pointed out by Kolpin et al. [29].

The concentrations of glyphosate in samples from the River Rhine were all between 25 and $55 \mathrm{ng} / \mathrm{L}$, while the concentrations of AMPA were between 55 and $65 \mathrm{ng} / \mathrm{L}$; glufosinate was not detected. The concentrations of glyphosate in the River Rhine are in a similar range to those of atrazine (see http://www.iksr.org), a herbicide which is still frequently used in Switzerland and is considered more mobile. These findings show that the relative importance of different sources (agriculture, weed control in urban areas, weed control on railway tracks) and the export of glyphosate to surface water are not fully understood so far.

Groundwater samples from ten different sampling stations in Switzerland did not show concentrations above the detection limit for any of the three analytes. Since glyphosate and AMPA sorb strongly to the soils, leaching into groundwater is not likely.

\section{Conclusion}

A method based on state-of-the-art equipment consisting of SPE enrichment and LC-MS/MS has been developed by optimizing several analytical steps. The low content of the organic modifier ACN during derivatization allowed the enrichment of larger sample volumes, resulting in improved sensitivity. Furthermore, the addition of EDTA helped to avoid analyte losses by complexation with multivalent metal cations. Additionally, a rinsing step with dichloromethane performed during SPE removed a considerable amount of the FMOC-OH. Finally, the limit of detection was lowered to $0.2 \mathrm{ng} / \mathrm{L}$, a level comparable to the LODs of other pesticides.

All of the optimizations led to a short and robust LCMS/MS method with a low detection limit that enables the fate of glyphosate in the aquatic environment to be traced.

Analysis of lake and river water samples clearly showed that detection at the low $n g / L$ level is crucial to enhancing our understanding of the behavior of glyphosate and its main metabolite in the aquatic environment. To assess the main sources and the important processes, more samples taken at different dates across the whole application period will need to be analyzed and compared to data on other frequently used herbicides.

Acknowledgements This project was funded by the Swiss Federal Office for the Environment, FOEN. We appreciate the contribution of Dorothea Kujawinski to improving the method. We thank Alfred Lück for sampling the lake water samples and Martin Frey for his support in mapping the sampling points, as well as Christa S. McArdell, Christian 
Stamm, and Martin Krauss for reading and reviewing the manuscript. We appreciate the help provided and interest shown by Stephan Müller, Edwin Müller and Georg Karlaganis from the Swiss FOEN.

\section{References}

1. Feng JC, Thompson DG (1990) J Agric Food Chem 38:1118 1125

2. Piccolo A, Celano G, Conte P (1996) J Agric Food Chem 44:2442 2446

3. Roy DN, Konar SK, Banerjee S, Charles DA, Thompson DG, Prasad R (1989) J Agric Food Chem 37:437 440

4. Vereecken H (2005) Pest Manag Sci 61:1139 1151

5. Rueppel ML, Brightwell BB, Schaefer J, Marvel JT (1977) J Agric Food Chem 25(3):517 528

6. Battaglin WA, Kolpin DW, Scribner EA, Kuivila KM, Sandstrom MW (2005) J Am Water Resour Assoc 41:323 332

7. Borjesson E, Torstensson L (2000) J Chromatogr A 886:207 216

8. Royer A, Beguin S, Tabet JC, Hulot S, Reding MA, Communal PY (2000) Anal Chem 72:3826 3832

9. Stalikas CD, Konidari CN (2001) J Chromatogr A 907:1 19

10. Ibañez M, Pozo OJ, Sancho JV, Lopez FJ, Hernandez F (2005) J Chromatogr A 1081:145 155

11. Vreeken RJ, Speksnijder P, Bobeldijk Pastorova I, Noij THM (1998) J Chromatogr A 794:187 199

12. Lee EA, Zimmerman LR, Bhullar SS, Thurman EM (2002) Anal Chem 74:4937 4943

13. Lee EA, Strahan AP, Thurman EM (2002) USGS Open File Rep 01454
14. Grey L, Nguyen B, Yang P (2001) J AOAC Int 84:1770 1780

15. Hidalgo C, Rios C, Hidalgo M, Salvado V, Sancho JV, Hernandez F (2004) J Chromatogr A 1035:153 157

16. Nedelkoska TV, Low GKC (2004) Anal Chim Acta 511:145 153

17. Zhu X, Cai J, Yang J, Su Q (2005) Carbohydr Res 340:1732 1738

18. Hogendoorn EA, Ossendrijver FM, Dijkman E, Baumann RA (1999) J Chromatogr A 833:67 73

19. Le Fur E, Colin R, Charreteur C, Dufau C, Peron JJ (2000) Analusis 28:813 818

20. Sancho JV, Hernandez F, Lopez FJ, Hogendoorn EA, Dijkman E (1996) J Chromatogr A 737:75 83

21. Ibañez M, Pozo OJ, Sancho JV, Lopez FJ, Hernandez F (2006) J Chromatogr A 1134:51 55

22. Freuze I, Jadas Hecart A, Royer A, Communal P Y (2007) J Chromatogr A 1175:197 206

23. ISO (2000) ISO Standard 11843 2: Capability of detection Part 2: Methodology in the linear calibration case. International Organization of Standardization, Geneva

24. Schuster R, Gratzfeld Hüsgen A (1992) Hewlett Packard Appli cation Note (Publication No. 1250913621 E). Hewlett Packard, Avondale, PA

25. Gauch R, Leuenberger U, Muller U (1989) Z Lebensm Unters Forsch 188:36 38

26. Roseboom H, Berkhoff CJ (1982) Anal Chim Acta 135:373 377

27. Ghanem A, Bados P, Kerhoas L, Dubroca J, Einhorn J (2007) Anal Chem 79:3794 3801

28. ISO (1990) ISO Standard 8466 1: Water quality Calibration and evaluation of analytical methods and estimation of performance characteristics Part 1: Statistical evaluation of the linear calibration function. International Organization of Standardization, Geneva

29. Kolpin DW, Thurman EM, Lee EA, Meyer MT, Furlong ET, Glassmeyer ST (2006) Sci Total Environ 354:191 197 